\title{
Global Green Shift: When Ceres Meets Gaia. By John Mathews. Anthem Press: New York, USA, 2017; 258 pp; ISBN-10: 1783086408
}

\author{
Dan Prud'homme \\ De Vinci Research Center, Léonard de Vinci Pôle Universitaire, 92916 Paris La Défense, France; \\ dan.prudhomme@devinci.fr
}

Received: 24 August 2018; Accepted: 28 August 2018; Published: 31 August 2018

In Global Green Shift: When Ceres Meets Gaia, John Mathews makes a fresh and compelling case for increasing the use of renewables and other green initiatives: what he calls a "green shift". Mathews provides a twist on previous environmentally-based arguments for green policies. He argues that the global green shift is really being driven by the need for energy security and new sources of economic revitalization. The fact that it can also prevent future environmental degradation and limit greenhouse gas emissions is, he argues, merely an added bonus. Further, Mathews' emphasis on neo-Schumpeterian economics, with creative destruction driving the global green shift, is very different from the "natural capital" approach advocated by other scholars, which focuses on how fast we use natural capital. Instead, Mathews concentrates on how we can manufacture our way out of trouble (with manufacturing being common to all renewable energy devices) and use industrial dynamics to drive down the costs of doing so. There is no real mechanism to drive down costs in the "natural capital" arguments.

The global green shift is tantamount to the process of ecological modernization ("eco-modernization"). Mathews discusses how eco-modernization allows a much needed reconciliation between economy and ecology. Through eco-modernization, economic processes are decoupled from natural resources. In other words, growth in purely physical activities is no longer needed to drive income, marking an evolution from the linear throughput model characterizing industrial development to date.

Mathews outlines several reasons why eco-modernization is a practical sustainable development strategy, and indeed is already being pursued by countries in Asia and elsewhere. First, eco-modernization is underpinned by renewable energy devices, whose manufacturing process is economically attractive due to industrial dynamics. Manufacturing benefits from economies of scale and increasing returns, as well as experience curves, which drive down costs. Manufacturing is also attractive because it generates jobs. Second, eco-modernization is feasible because global population growth is predicted to plateau by around 2050, allowing the process to work within reasonable human consumption constraints. Third, eco-modernization relies on urbanization, which is already an ongoing process around the world that generates a range of positive externalities. Fourth, eco-modernization relies on "investment choices", and therefore is more appealing to a wider range of economic agents than alternative processes that primarily dis-incentivize behavior.

Mathews argues that eco-modernization's emphasis on renewable energy technologies is not only practical, but necessary to states because it affords them energy security. Energy security is especially critical for large latecomer nations such as China, India, and Brazil because of their high demand for resources. Renewable energy technologies are manufactured and do not rely on exhaustible energy sources. These attributes allow states to develop the capacity to manufacture such technologies (e.g., wind turbines and solar panels) and rely on inexhaustible energy sources (e.g., the sun and wind) to power them. In turn, this energy security allows economies to move away from the heavy reliance 
on exhaustible natural resource endowments of other states, including nations constantly embroiled in turmoil.

Indeed, it is difficult to argue that fossil fuel-based trajectories can serve as the economic model for all of today's emerging economies as they seek to catch up. If such trajectories are followed, i.e., "business as usual" continues, the environmental consequences and, perhaps more immediately, social consequences in terms of conflict over fossil fuels and other natural resources, will likely be dire. Wars, revolutions, and other conflicts throughout history make this abundantly clear.

Mathews delves into a more granular discussion of the strategic economic benefits of increased production and global diffusion of renewables. He argues that economies can generate rising incomes and domestic employment from renewable energy technologies and their associated value chains. The gains can even potentially be felt in declining manufacturing regions in rural areas. Also, the technologies have close to zero running costs since they do not need fuel, benefit from economies of scale, are scalable given their modularity, and are replicable in cities around the world. This is especially attractive to pragmatic latecomers (e.g., China) pressed to find new sources of growth. Forerunner states should also be attracted by renewables for similar reasons, although the benefits are often overshadowed by Olsonian barriers (e.g., the fossil fuel lobby).

Mathews is justified in suggesting that capitalism is the most practical model to enable a global green shift. So-called "zero-growth" policies, meaning those only favoring environmental conservation and not economic growth, are impractical methods to address the resource constraints confronting today's economies. Generally speaking, capitalism has served as a steady engine of economic growth to date. It is surely still needed, at least in some form, by emerging economies (e.g., China, India, and Brazil) to raise, via increasing returns, their peoples' incomes and quality of life. Therefore, rather than being abandoned, capitalism should be transformed to better take advantage of the challenges posed by the fossil-fuel model and the opportunities brought by renewable energy and other green initiatives. Mathews makes this powerful pro-business argument in another recent work of his, Greening of Capitalism: How Asia is Driving the Next Great Transformation (SUP, 2015).

This grand realization has led to the emergence, perhaps circa 2010 according to Mathews, of a third phase of global industrialization driven by renewable energies and other green innovations. This phase follows the agrarian economy and subsequent fossil-fuel industrialized economy phase of economic history, which, to its credit, has lifted many of out of poverty and enabled avoidance of the Malthusian trap.

Perhaps surprisingly, Mathews notes that the third phase of global industrialization has already produced much of the fundamental technology needed to overcome the most pressing resource constraints we currently face. Mathews illustrates how useful renewable energy technologies and methods of connecting them to the power grid, as well as other green innovations (e.g., sustainable food and water production technologies and practices), already exist. They include wind and solar technologies for energy generation, lithium-ion batteries for energy storage, and IT-enabled grids for energy transmission. However, Mathews goes on to suggest that, despite the practicability of the global green shift owing to existing technological competencies, ensuring adequate diffusion of these technologies is a pressing challenge at present.

Mathews goes on to outline other benefits of renewable energy technologies and explain why their adoption is more practical than some have argued. He discusses how, among other advantages, renewable energy technologies are clean and benign, unlike fossil fuels whose extraction and use is more prone to hazards. He interestingly illustrates how economies can shift to renewables using far less land mass than what some have previously predicted - effectively debunking the "myth of Renewistan".

Although the third wave of global industrialization is already upon us and the adoption of existing green technologies is an important next step in this process, Mathews notes that a "sixth wave" $(6 \mathrm{w})$ of Schumpeterian creative destruction-led by eco-modernization-is a very much ongoing part of this transformation. This $6 \mathrm{w}$ of creative destruction (also known as the sixth major techno-economic 
paradigm) follows the diffusion of IT and microelectronics (5w), oil drilling technology (4w), expanded electricity grids $(3 w)$, railways $(2 w)$, and the steam engine (the $1 w)$.

Guided by these arguments, Mathews illustrates how much of our world's green shift is taking place through "CERES", a circular economy and renewable energy system. Mathews likens CERES to the Roman goddess Ceres, who he sees uniting with Gaia, the Greek mother earth goddess. Within this narrative, Global Green Shift: When Ceres Meets Gaia discusses a range of modern-day CERES initiatives.

Mathews rightly suggests that the Chinese state acutely realizes the benefit of CERES. The system affords China energy security, as well as an opportunity to economically capitalize on eco-efficiencies, connect to global value chains, upgrade in "crisscrossing" value chains, specialize in innovation, boost domestic employment and export opportunities, and avoid domestic social unrest. Several examples of China's CERES initiatives are outlined. The Chinese state has set a target to generate a whopping 750 GW of clean energy (from water, wind, and sun) by 2020. In 2015, China's per capita investment in clean energy overtook that of the EU. A variety of circular economy policies have been promulgated at the central and sub-central levels. In 2015, China was the first country to issue a specific and official set of guidelines governing green securities. Mathews suggests that some eco-cities in China are taking off, although others are admittedly underperforming. China has also deployed a host of other policies for green economic activity, including low interest loans, subsidies, and land grants.

As expected for a business scholar, Mathews provides a number of interesting case studies of CERES initiatives from Asia, Australia, the US, and elsewhere. He profiles Sky Greens, a Singapore venture that uses vertical farming to produce a variety of freshly grown vegetables. He profiles Mirai, a Japanese firm that partnered with GE to produce lettuce at one hundred times the productivity of traditional farming. A number of other firms are also briefly profiled, including Memphis Meats, a firm producing in-vitro meat; Perfect Day Co., who produces milk from bio-engineered yeasts; Sundrop Farms, who grows crops using only clean and sustainable inputs; among other firms. Fittingly symbolic of the neo-Asian entrepreneurialism driving the global green shift, Mathews invited the founder of Suntech Power-a Chinese firm and the world's largest producers of solar panels-to author the foreword of Global Green Shift.

Several questions came to mind while reading Global Green Shift that may provide fertile ground for future research. First, how can better renewable energy storage technology be developed to address the problem of intermittent energy? And how can China in particular best tackle their curtailment problem (i.e., the fact that a significant amount of power generated in the country is not ultimately fed into the grid)? Second, how does rising automation around the world impact the ability of states to generate manufacturing jobs in the area of renewable energy technologies? Third, to what extent, if at all, should states indigenously manufacture rather than import foreign-manufactured renewable energy technologies to ensure energy security? Fourth, how exactly can the composition of the natural landscape (not just land mass per se) as well as sun, wind, geothermal, and water availability be managed to make CERES more feasible? Fifth, how can plurilateral rather than mandatory agreements in the World Trade Organization (WTO), such as the Global Procurement Agreement, best be designed to allow nations flexibility to use controversial yet potentially effective policies for green growth, such as local content requirements? Sixth, how can states best design policies that overcome the coordination costs between firms and other economic agents currently limiting the effectiveness of circular economy initiatives? Seventh, what is the best way for regulators to govern the sale of products that are important for green growth yet result from unconventional processes, such as in-vitro/cultured meat?

In sum, Global Green Shift: When Ceres Meets Gaia is a highly recommend read. It is useful for scholars interested in gleaning important insights and inspiration for future research into one of the most pressing issues of our time.

(C) 2018 by the author. Licensee MDPI, Basel, Switzerland. This article is an open access article distributed under the terms and conditions of the Creative Commons Attribution (CC BY) license (http:/ / creativecommons.org/licenses/by/4.0/). 